\section{In Newton's shadow}

\section{Willem Hackmann}

Before Newton. The Life and Times of Isaac Barrow. Edited by Mordechai Feingold. Cambridge University Press: 1990. Pp. 380. £35, \$49.50.

When one thinks of Isaac Barrow one immediately thinks of Isaac Newton, and that has been the misfortune of one of the most prominent seventeenth-century mathematicians and men of science. History has not treated him kindly.

Barrow's reputation was quickly put in the shade by the successor to his Lucasian chair of mathematics at Cambridge, the incomparable Newton, whom Barrow supported successfully for the post. His reward has been that he has remained a rather shadowy figure which this biography, consisting of a collection of chapters by Barrovian authorities, attempts to illuminate.

According to an earlier biographer, Barrow was known to his contemporaries for his slovenly ways, his excessively long sermons, and his great learning. $\mathrm{He}$ is best remembered for his mathematical and optical writings. History always has difficulty in judging a polymath and that is what Barrow was in seventeenthcentury terms. Others have judged him an ambitious careerist. Certainly, as this biography shows, ability did nct get one far without patronage. Barrow was lucky with his patrons both in and outside Cambridge. He was educated at Charterhouse, Felstead School and Trinity College, Cambridge, where he was successively a pensioner (1643), college fellow (1649), and Master (1673). His first attempt at the Regius professorship of Greek failed for politico-religious reasons (Cambridge was in the throes of the Civil War), but his second attempt (1660) at the restoration of the monarchy was successful. Subsequently he became Gresham professor of geometry in London (1662), thereby supplementing his meagre Cambridge income, the first Lucasian professor of mathematics (1663), Royal Chaplain to Charles II in London (1669), and finally Vice-Chancellor of Cambridge (1675).

Barrow's misfortune was, as Feingold points out in his introductory chapter 'Isaac Barrow: divine, scholar, mathematician', that he was active at the turning point of classical culture in the mid-seven- teenth century - a learned culture that became virtually obsolete in Barrow's lifetime, when a more narrow scholarly professionalism started to creep in. Past historians of science, too, have largely ignored Barrow in their quest for the 'giants' of the scientific revolution, and his name is linked to no discovery. Thus, Barrow became chiefly remembered as the mentor of Newton, but even this relationship has never been clarified. That Newton was Barrow's pupil at Trinity is a myth. His name does not appear in

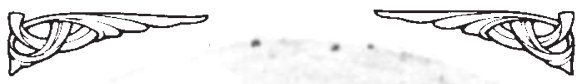
\section{spicuously absent from Barrow's library catalogue.}

Barrow's optical and mathematical contributions have been very adequately dealt with in Alan Shapiro's chapter, entitled 'The Optical Lectures and the foundations of the theory of optical imagery', and in Michael Mahony's 'Barrow's mathematics: between ancients and moderns'. Shapiro points out that Barrow completed a major phase of the Keplerian revolution in geometrical optics by creating a mathematical theory of optical imagery. The weakness was that he did not deal with applied optics and such topics as the eye and vision, the telescope and microscope. Other biographers, notably

Whiteside, have been less kindly about Barrow's optics, but he does agree that his most original contributions were his method for finding the point of refraction at a plane interface and his point construction of the diacaustic of a spherical interface. In mathematics Barrow and Newton were pursuing quite different paths. Barrow preferred the analysis of geometrical configurations; Newton's fluxions (his form of calculus) clearly lay in the algebraic tradition.

Barrow emerges from these pages a scholar in the humanist tradition (VIDE Anthony Grafton's brief chapter, 'Barrow as a scholar'), a sincere man with a gentle temper (see Irène Simon's equally short chapter, 'The preacher') and, to give the final word to the editor of this volume, a man whose integrity is the recurring motif of his life.

Insight into the relationship between Barrow and Newton is also somewhat unexpectedly given in the final chapter in this volume in which Feingold describes Barrow's library. As his first biographer, Abraham Hill, wrote, the estate left by Barrow "was books". Of his library of 1,100 volumes, predictably for the period more
Willem Hackmann is in the Museum of the History of Science, Broad Street, Oxford OX1 $3 A Z$, UK.

The picture shows Isaac Barrow in 1676 (courtesy of the National Portrait Gallery). 